\title{
Brazilian Journal of Chemical

\section{THE COMPLETE MODELLING OF THE FILLING PROCESS OF HYDROGEN ONBOARD VEHICLE CYLINDERS}

\author{
M. Deymi-Dashtebayaz ${ }^{1 *}$, M. Farzaneh-Gord ${ }^{2}$, N. Nooralipoor ${ }^{2}$ and H. Niazmand ${ }^{3}$ \\ ${ }^{1}$ Hakim Sabzevari University, Faculty Member of Mechanical Engineering, Sabzevar, Iran. \\ Phone: 0098 5144012814; Fax: 00985144012773 \\ E-mail: meh_deimi@yahoo.com \\ ${ }^{2}$ The Faculty of Mechanical Engineering, Shahrood University of Technology, Shahrood, Iran. \\ E-mail:mahmood.farzaneh@yahoo.co.uk; navid.nap@gmail.com \\ ${ }^{3}$ Mechanical Engineering Department, Ferdowsi University of Mashhad, Mashhad, Iran. \\ E-mail: Niazmand@um.ac.ir
}

(Submitted: December 21, 2014 ; Revised: March 28, 2015 ; Accepted: May 8, 2015)

\begin{abstract}
Complete modelling of the filling process occurring in a hydrogen-fueled vehicle storage cylinder is examined. A simultaneous modelling of the flow and heat transfer within the cylinder and cylinder wall has not been considered in previous studies. Rapid filling may result to an unexpected temperature rise and breaching of the safety standards. In the present study, initially a correlation was developed based on a numerical simulation for predicting the heat transfer rate between in-cylinder flow and the cylinder inside wall. Then, a thermodynamic model was developed for predicting transient variations of temperature and pressure inside the cylinder and wall temperature during the filling. The model was applied to a type III onboard storage cylinder filling process. The numerical results are compared with previously measured values and showed good agreement. The results also show that a great portion of heat dissipation from the incylinder flow is stored in the cylinder wall. It is also found that ambient temperature during the refueling process has considerable effects on filling behavior in general and in particular on the final in-cylinder temperature and filled mass.

Keywords: Hydrogen fuelling station; Fast-filling process; Heat transfer rate; Complete thermodynamic modelling.
\end{abstract}

\section{INTRODUCTION}

Utilization of hydrogen as a clean alternative fuel has a favourable impact on the environment (Farzaneh-Gord et al., 2013a). Being cleaner and more effective than petrol, hydrogen has been recognized as the primary choice for future fuels in automobiles (Maus et al., 2008; Zhao et al., 2012). Because of the recent developments in hydrogen fuel technology, the spread of hydrogen fuelling stations has gained more attention in the world (Rigas and Sklavounos, 2005; Schoenung et al., 2006). Studies indicates that 80 to $90 \%$ of hydrogen is stored using high-pressure compression in hydrogen fuelling stations and vehicle cylinders (Tzimas and Filiou, 2003), due to the advantages of being more practical, dependable, durable and admissible (Zheng et al., 2008; Maus et al., 2008; Zhang et al., 2006) as compared to other methods.

In this system, fuel is delivered from high-pressure hydrogen reservoirs into the onboard vehicle cylinder. The station dispensers control the rate of hydrogen passing into the cylinder and therefore the rate of temperature/pressure rise inside the cylinder. Clearly, reducing filling time has a favourable impact on commercialization of hydrogen vehicles, yet it

*To whom correspondence should be addressed 
may result in unexpected temperature rise and breaching of the safety standards (Zhao et al., 2012; ISO15869 2005; ISO11439 2005). Due to the importance of temperature rise during the filling process, several experimental, numerical and theoretical studies have been performed on the issue. Yang (2009) developed a thermodynamic and heat transfer analysis of an onboard cylinder hydrogen refuelling process. The cylinder was assumed to be adiabatic, isothermal, or diathermal, while hydrogen was considered to be both an ideal and a real gas with a constant inlet flow rate. For an ideal gas, simple analytical expressions are derived for the tank temperature and pressure during adiabatic, isothermal, and diathermal refuelling conditions. Non-ideality is treated using the newly developed equation of state for normal hydrogen based on the reduced Helmholtz free energy formulation. Lower tank temperatures and pressures and longer filling times are always predicted when the real gas assumption is applied.

In another study, Mohamed and Paraschivoiu (2005) modelled hydrogen release from a high-pressure chamber based on the real gas assumption. Zheng et al. (2010) simulated an optimizing control method for a high utilization ratio and fast filling speed in hydrogen fuelling stations. It was shown that the optimizing control method can meaningfully improve the utilization ratio, while allowing for acceptable refuelling time. Farzaneh-Gord et al. (2012a) have also carried out a theoretical analysis to study the effects of storage types and conditions on the performance of hydrogen filling stations and the filling process for an adiabatic cylinder.

Liss and Richards (2002), Liss et al. (2003), Newhouse and Liss (1999), Chan Kim et al. (2010) and Liu et al. (2010) have examined the fast filling of hydrogen cylinder experimentally. They all reported a high temperature rise in the cylinder during the fast filling process. Chan Kim et al. (2010) have also studied the thermal characteristics of a type IV cylinder filling process using computational fluid dynamics (CFD) analysis. The results show good agreement with the experiments, specifically as the initial in-cylinder pressure increases. Similar CFD analysis has been carried out by Heitsch et al. (2011), where the fast filling process of hydrogen tanks is simulated. It was found that the local temperature distribution in the tank depends on the materials of the liner and the outer thermal insulation. Different material combinations (type III and IV) were investigated. Dicken and Merida (2008) have also modelled the filling process of a hydrogen cylinder using CFD tools and experiments. They computed the heat transfer rate from in-cylinder gas to the ambient numerically but failed to present a general correlation.

Since the hydrogen and Compressed Natural Gas (CNG) infrastructures are similar, it is also constructive to consider the comparable studies on $\mathrm{CNG}$ (Thomas et al., 2002; Shipley, 2002). These studies also reported a temperature rise of about $40 \mathrm{~K}$ during the filling process of storage gas cylinders. The temperature rise reduces the density of filled gas, resulting in an under-filled cylinder relative to its rated specification. It was also found that ambient temperature influences the filling process and storage capacity (Shipley, 2002).

Farzaneh-Gord et al. (2007, 2008a, 2008b, 2011, $2012 b, 2012 c, 2013 b)$ have also simulated the fast filling process of CNG in several studies. The results indicated that ambient temperature has considerable effects on the filling process and final cylinder conditions. They also employed a theoretical analysis to study the effects of buffer and cascade storage tanks on the performance of a CNG fuelling station (Farzaneh-Gord et al., 2011). The effects of natural gas compositions on the fast filling process for buffer and cascade storage tanks have also been examined (Farzaneh-Gord et al., 2012b, 2012c). The storage tanks are treated as adiabatic in all of their studies.

Nooralipour and Farzaneh-Gord (2013) studied the CNG fast filling process using commercial CFD software. Although their numerical findings compare well with the available experimental data, the computations were so time demanding that some improvements in the modelling are necessary. Also in another study, Deymi-Dashtebayaz et al. (2014) presented the full simulation of rapid refuelling of a CNG Vehicle on-board cylinder.

The above review of related literature indicates a shortage of information regarding the thermal aspect of the hydrogen cylinder fast filling process. In the present study, initially the filling process is numerically modelled to evaluate the heat transfer rate between in-cylinder gas and the cylinder wall by developing a correlation for predicting the inner convective heat transfer coefficient. Then, with the help of the developed correlation, a simultaneous thermodynamic modelling of the in-cylinder gas and cylinder wall was performed for predicting the thermal characteristics of the filling process with reasonable accuracy and minimal computational cost.

\section{THE METHOD AND MODELLING}

Figure 1 shows an on-board storage cylinder which receives the compressed gas from high-pressure 
storages. The fuel flows through connection pipes and enters the cylinder through the inlet tube. In the actual condition, the rate of flow is controlled by the dispensers control algorithm. Here, the inlet temperature/pressure and mass flow rate are taken from experiments carried out by Dicken and Merida (2007, 2008).

As mentioned earlier, the filling process of the cylinder is modelled numerically by a CFD package (Fluent), which is discussed in the next section. Later, the complete thermodynamic modeling of the filling process will be discussed.

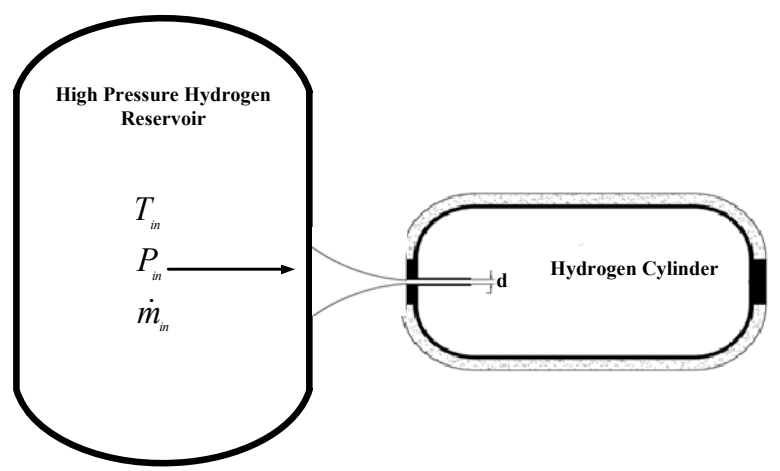

Figure 1: A schematic diagram of the problem under investigation.

\section{CFD Modelling}

A schematic diagram of the onboard cylinder for CFD calculations is shown in Figure 2. The cylinder is type III with the internal volume of $74.1 \mathrm{~L}$. The external diameter and length are 39.6 and $89.3 \mathrm{~cm}$, respectively. The cylinder wall consists of an aluminium liner, which is laminated with an epoxy laden carbon-fibre wrap. The cylinder specifications and inlet conditions are taken from Dicken and Merida (2007, 2008), which also provides the experimental data needed for validation of the numerical results.

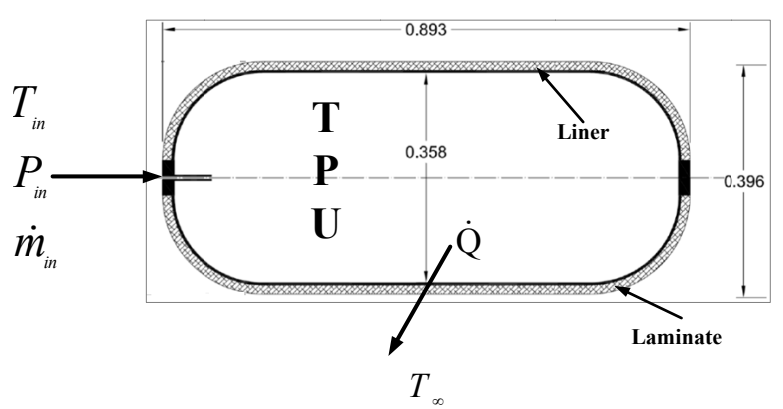

Figure 2: A schematic diagram of the hydrogen onboard cylinder
The grid structure used for computations is a combination of structured and unstructured meshes as shown in Figure 3. Relatively fine grids are utilized around the inlet area, where the highest gradients are expected. The cylinder walls are modelled by a structured mesh, while the unstructured grid distribution is used for the in-cylinder volume. More details about the CFD method can be found in Nooralipour and Farzaneh-Gord (2013).

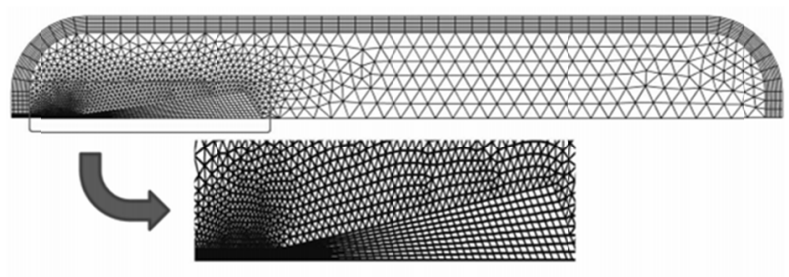

Figure 3: The computational grind used in this study.

\section{The Thermodynamic Analysis}

\section{Energy Equation for Inside the Cylinder}

To simulate the fast filling process and construct a thermodynamic model, the hydrogen onboard cylinder is treated as a thermodynamic open system that goes through a quasi-steady process. Applying the conservation of mass to the cylinder as a control volume with only one inlet leads to:

$\frac{d m_{C}}{d t}=\dot{m}_{i}$

where $\dot{m}_{i}$ is the inlet mass flow rate taken from the experimental study of Dicken and Merida (2007, 2008) for validation purposes, as mentioned earlier.

The first law of thermodynamics for the control volume can be written as:

$\frac{d U_{C}}{d t}=\delta \dot{Q}+\dot{m}_{i}\left(\frac{V e_{i}^{2}}{2}+h_{i}\right)$

The inlet velocity, $V e_{i}$, is calculated based on the known mass flow rate:

$V e_{i}=\frac{\dot{m}_{i}}{\rho_{i} A_{i}}$

where $\rho_{i}$ and $A_{i}$ are the inlet density and the cross sectional area of the inlet pipe, respectively. The inlet 
density and $\rho_{i}$ can be calculated from the known values of the inlet temperature and pressure. In the present study, these properties are chosen to be identical to the values reported by Dicken and Merida (2007, 2008).

Also the Reynolds and Mach numbers in the inlet could be obtained as:

$$
\begin{aligned}
& R e_{i}=\frac{4 \dot{m}_{i}}{\pi \mu_{i} d_{i}} \\
& M a_{i}=\frac{V e_{i}}{C_{i}}
\end{aligned}
$$

where $R e_{i}, M a_{i}, d_{i}$ and $\mu_{i}$ are the Reynolds and Mach numbers, diameter and viscosity of the inlet cylinder.

The heat released from the in-cylinder gas to the wall is calculated according to:

$$
\delta \dot{Q}=\alpha_{i} A_{C}\left(T_{C}-T_{i w}\right)
$$

where $\alpha_{i}, A_{C}, T_{C}$, and $T_{i w}$ are the internal convection heat transfer coefficient, cylinder surface area, incylinder gas temperature and inside-wall temperature, respectively. $\alpha_{i}$ can be calculated by employing the definition of the Nusselt $(\mathrm{Nu})$ number:

$$
N u=\frac{\alpha_{i} d}{K}
$$

where $K$ and $d$ are the thermal conductivity coefficient for in-cylinder hydrogen gas at its temperature and the inside diameter of the inlet tube, respectively.

To our best knowledge there is no correlation available for variations of the heat transfer rate during the filling process of a compressed hydrogen onboard cylinder. In the present study, the following correlation was developed based on CFD results for the Nusselt number (Deymi-Dashtebayaz et al., 2014):

$$
N u= \begin{cases}22512 \times \dot{m}_{R A}+1163.4 & \text { IF } \dot{m}_{R A}<0.03 \\ 22358 \times \dot{m}_{R A} 0.7184 & \text { IF } \dot{m}_{R A} \geq 0.03\end{cases}
$$

where $\dot{m}_{R A}$ is the ratio of inlet mass flow rate, $\dot{m}$, to the maximum mass flow rate, $\dot{m}_{\max }$ :

$$
\dot{m}_{R A}=\frac{\dot{m}}{\dot{m}_{\max }}
$$

Maximum mass flow rate occurs in the choking condition and can be calculated according to Costhuizen and Carscallen (1997):

$\dot{m}_{\max }=A \sqrt{\delta \rho_{0} P_{0}\left(\frac{2}{\delta+1}\right)^{\left(\frac{\delta+1}{\delta-1}\right)}}$

where $\delta, \rho_{0}$ and $P_{0}$ are the isentropic exponent, density, and pressure of the high pressure hydrogen reservoir, respectively.

Combining Equations (1), (2) and (6), the following equation is obtained:

$\frac{d\left(m_{C} u_{C}\right)}{d t}-\frac{d\left(m_{C}\right)}{d t}\left(\frac{V e_{i}^{2}}{2}+h_{i}\right)=-\alpha_{i} A_{C}\left(T_{C}-T_{i w}\right)(11)$

which can be rearranged to:

$d\left(m_{C} u_{C}-m_{C}\left(\frac{V e_{i}^{2}}{2}+h_{i}\right)\right)=-\alpha_{i} A_{C}\left(T_{C}-T_{i w}\right) d t$

If the inside wall temperature, $T_{i w}$, and the internal heat transfer coefficient are known (or the cylinder is assumed to be adiabatic), then from equations 10 and 1 the in-cylinder gas density and internal energy can be determined. Other thermodynamic properties are then obtained from thermodynamic tables. Farzaneh-Gord et al. (2007, 2008a, 2008b, 2011, 2012a, 2012b, 2013a) have used the same method to analyse the filling process of an adiabatic cylinder. Here, the energy equation for the cylinder wall was also solved simultaneously to determine the inside wall temperature.

\section{The Energy Equation for the Cylinder Wall}

Heat transfer between hydrogen and the ambient includes convective heat transfer between in-cylinder hydrogen and the inside wall, heat conduction within the wall and finally free convection heat transfer between the exterior wall and ambient. The cylinder wall is made of a highly conductive aluminium liner and a comparatively insulating carbon fibre and epoxy wrapping. For simplicity, the thermal properties of both liner and laminate are assumed to be constant. The in-cylinder temperature rise is affected by the material properties of the liner and laminate.

The cylinder wall is divided into two control volumes (liner and laminate) and the energy equation was applied to both systems according to: 


$$
\begin{aligned}
&\left(\rho C_{p} x\left(\frac{\partial T}{\partial t}\right)\right)_{\text {Liner }}=\alpha_{i}\left(T_{C}-T_{i w}\right)-\left(\gamma\left(\frac{\partial T}{\partial x}\right)\right)_{\text {Liner }} \\
&\left(\rho C_{p} x\left(\frac{\partial T}{\partial t}\right)\right)_{\text {La min ate }}=\left(\lambda\left(\frac{\partial T}{\partial x}\right)\right)_{\text {La min ate }} \\
&-\alpha_{o}\left(T_{\mathrm{ow}}-T_{\infty}\right)
\end{aligned}
$$

In above equations $\rho, C_{p}, \mathrm{~T}_{\infty}, x$ and $\lambda$ are the density, specific heat, ambient temperature, thickness and thermal conductivity for the liner or laminate layers, respectively. $\alpha_{o}$ is the natural convective heat transfer coefficient between the ambient and outside wall, which is assumed to be constant and equal to $10 \mathrm{~W} / \mathrm{m}^{2} \mathrm{~K}$ (Dicken and Merida 2008).

Clearly, the conductive heat fluxes must be equal at the interface of the layers.

$$
\left(\lambda\left(\frac{\partial T}{\partial x}\right)\right)_{\text {Liner }}=\left(\lambda\left(\frac{\partial T}{\partial x}\right)\right)_{\text {La minate }}
$$

By solving Equations (13), (14) and (15) simultaneously, the time variations of the inside wall temperature can be obtained during the filling process.

\section{The Numerical Solution Procedure}

Calculation of the in-cylinder hydrogen thermodynamic properties begins with solving Eq. (1) by a first order Euler scheme to determine the hydrogen mass within the cylinder at a given time step. Knowing the volume of the cylinder, the specific volume of hydrogen can be easily obtained. Then, Eqs. (11), (12) and (13) are solved simultaneously to find the inside wall temperature and in-cylinder hydrogen specific internal energy at the new time step. Upon knowing two independent thermodynamic properties (here specific internal energy and specific volume), other thermodynamics properties (pressure, temperature) can be easily obtained from hydrogen property tables.

\section{Boundary Conditions and Material Properties}

The ambient temperature is kept constant at 293.4 $\mathrm{K}$ throughout the fill. The time variations of the inlet pressure, temperature and mass flow rate are shown in Figures 4 and 5 according to the measured values of Dicken and Merida (2008).

The material properties of the cylinder wall are listed in Table 1.

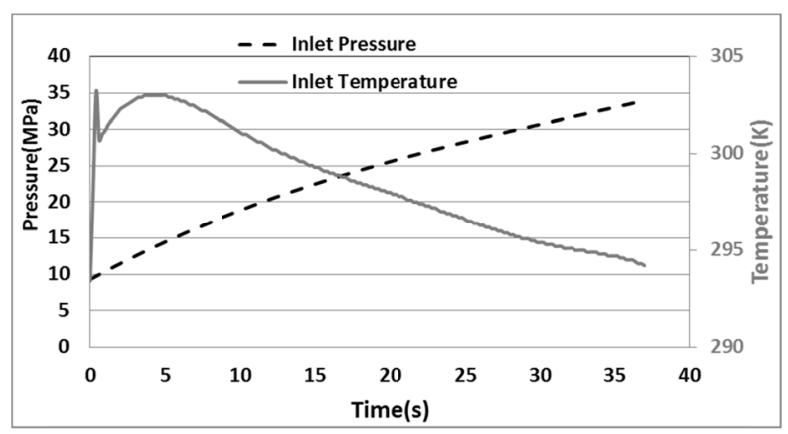

Figure 4: Experimentally measured inlet gas temperature and pressure reported by Dicken and Merida (2008)

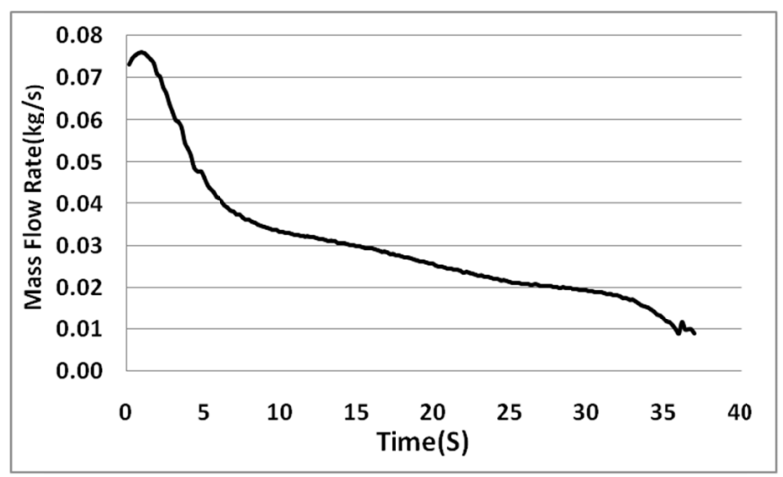

Figure 5: Measured mass flow rate of gas entering the cylinder throughout the fill (Dicken and Merida 2008).

Table 1: Material properties of the cylinder wall (Dicken and Merida, 2008).

\begin{tabular}{|c|c|c|c|c|}
\hline & $\begin{array}{c}\text { Thickness } \\
\mathbf{x} \\
(\mathbf{m})\end{array}$ & $\begin{array}{c}\text { Density } \\
\boldsymbol{\rho} \\
\left.\mathbf{k g} / \mathbf{m}^{\mathbf{3}}\right)\end{array}$ & $\begin{array}{c}\text { Specific heat } \\
\mathbf{C p} \\
(\mathbf{J} / \mathbf{k g} \mathbf{K})\end{array}$ & $\begin{array}{c}\text { Thermal } \\
\text { conductivity } \\
\mathbf{K}(\mathbf{W} / \mathbf{m} \mathbf{K})\end{array}$ \\
\hline $\begin{array}{c}\text { Liner } \\
\text { The carbon } \\
\text { fibre epoxy }\end{array}$ & 0.004 & 900 & 2730 & 167 \\
& 0.015 & 938 & 1494 & 1 \\
\hline
\end{tabular}

\section{RESULTS AND DISCUSSION}

In this study, the inlet tube diameter and cylinder volume are considered to be $5 \mathrm{~mm}$ and 74 litters (Dicken and Merida, 2008), respectively.

The numerical results were first validated against the measured values of Dicken and Merida (2008). In addition to the experimental work, they carried out a numerical study of the fast filling process of compressed hydrogen gas. Although they modelled the filling process numerically (using a CFX package), they did not present any correlation for the heat transfer coefficient. 
In the first step of the validation of the method for calculation of the physical properties of hydrogen gas during the filling process, the calculated gas density was compared with density values obtained from the National Institute of Standards and Technology (NIST). As shown in Figure 6, there is good agreement between the results of this work and NIST density values.

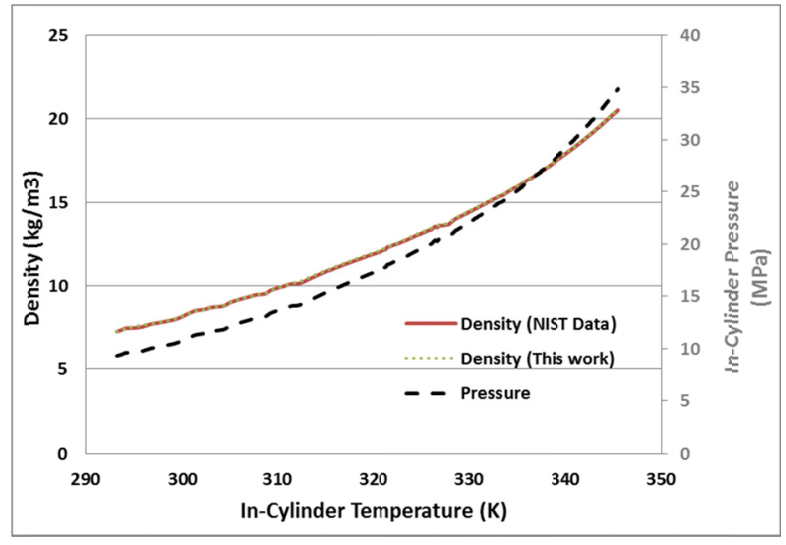

Figure 6: Comparing the density of hydrogen gas calculated in this work during the filling process and NIST values.

Figure 7 presents the variations of the Reynolds and Mach numbers during the hydrogen gas filling process. As shown in this figure, the average Reynolds number at the inlet is on the order of $10^{5}$. Accordingly, it can be concluded the flow at the inlet is turbulent. Also for the Mach number, as illustrated in the figure, during the filling process the inlet conditions remain in the subsonic condition.

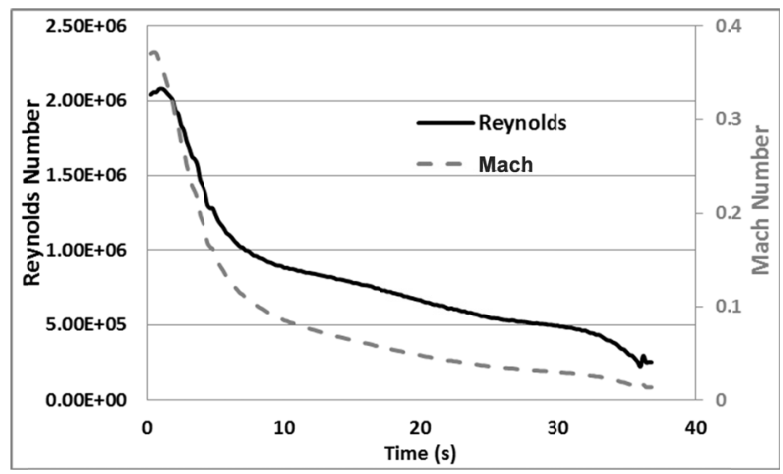

Figure 7: Variations of Reynolds and Mach numbers during the hydrogen gas filling process.

Figure 8 shows a comparison between the measured and numerical values of the in-cylinder average gas pressure. It is clear that the pressure increases almost linearly within the cylinder. Reasonable agreement can be observed between the measured and numerical results.

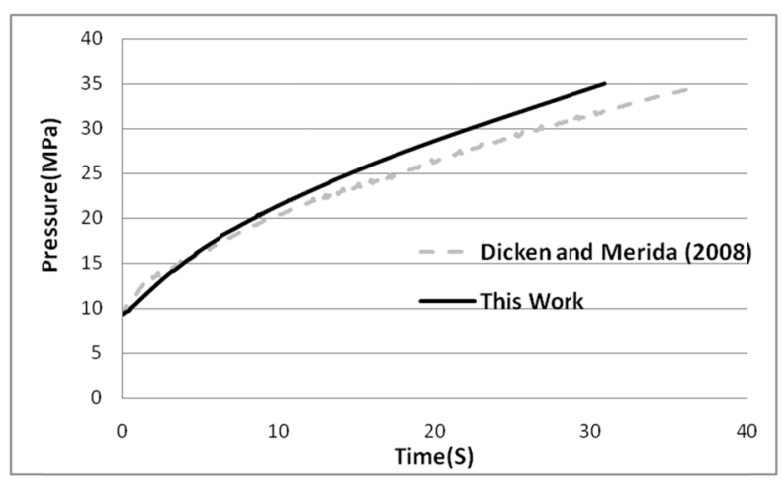

Figure 8: Comparing the numerical and the measured in-cylinder pressures of Dicken and Merida (2008) for the compressed hydro.gen gas filling process.

Figure 9 shows a comparison between the measured and numerical time variations of the in-cylinder average gas temperature, indicating reasonably good agreement. For compressed hydrogen gas under the given conditions, the temperature rise can reach $55 \mathrm{~K}$.

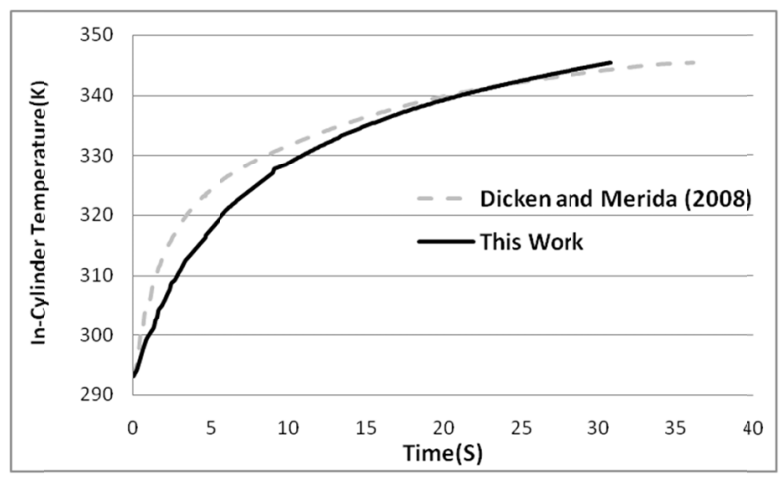

Figure 9: Comparing the numerical and the measured in-cylinder temperatures of Dicken and Merida (2008) for the compressed hydrogen gas filling process.

During the filling, due to the temperature difference between the compressed gas and the inner wall of cylinder, heat transfers from gas to the wall. In Figure 10 the time variation of the heat transfer rate from the compressed gas to the cylinder wall is compared with the experimental findings of Dicken and Merida (2008). Clearly, the highest heat flux to the wall occurs at early times of filling, which can reach as high as $60 \mathrm{~kW}$. Again a relatively good agreement can be seen between the measured and numerical values. 
Figure 11 describes the temperature variations of the inside and outside walls during the fill. The temperature profiles of the cylinder wall show the dramatic effect of the thermal conductivity of the liner and carbon epoxy fibber materials. The time variation of temperature within the aluminium liner is almost the same as that of the in-cylinder gas temperature due to the high thermal conductivity of aluminium. However, due to the relatively fast speed of the filling process and the low thermal conductivity of the laminate, the external surface temperature of the cylinder remains almost constant at ambient temperature. Consequently, it can be concluded most of heat dissipation from the in-cylinder flow is stored in the cylinder wall. Also, the in-cylinder gas and the cylinder wall could be considered as a combined adiabatic system for the type III cylinder.

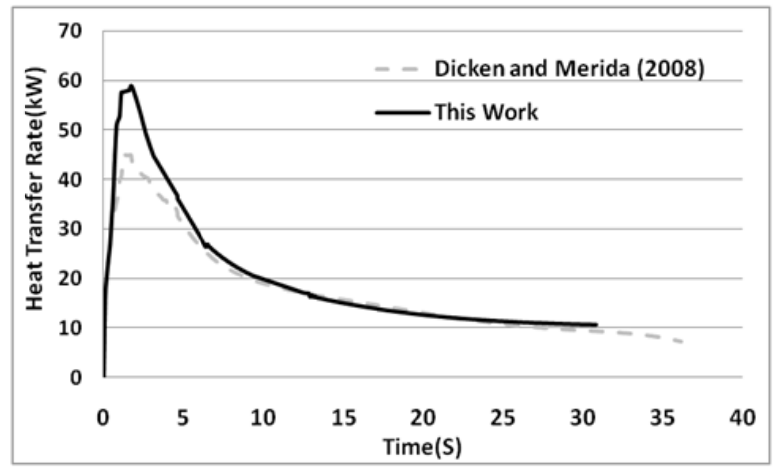

Figure 10: Heat transfer rate from in-cylinder to the wall during the filling.

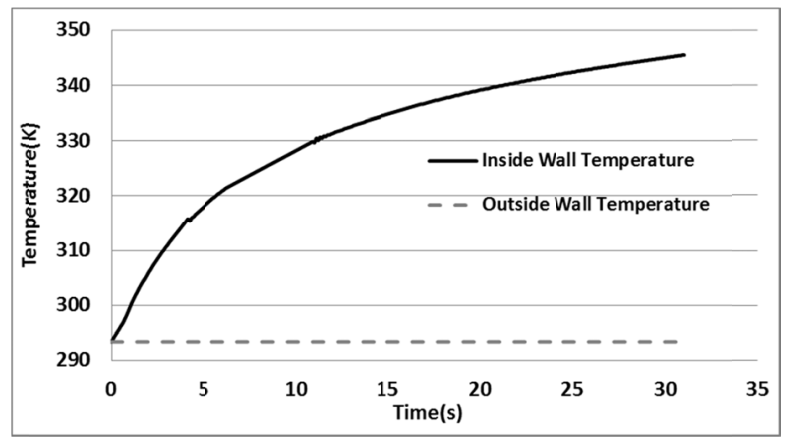

Figure 11: Model predicted temperature profile in the cylinder wall during filling.

Previous studies (Farzaneh-Gord et al., 2007, 2008a, 2008b, 2011, 2012a, 2012b, 2013a) showed that the initial in-cylinder temperature, which is basically the same as the ambient temperature has significant effects on the final in-cylinder temperature and charged mass. Figure 12 shows the variation of charged mass with ambient temperature, which indicates an almost linear drop as the ambient temperature increases. This means that the driving range of hydrogen vehicles reduces for fills in hot summer time as compared to the cold winter condition. As expected, the rise in ambient temperature also increases the final in-cylinder gas temperature. It is interesting to note that this variation is almost linear.

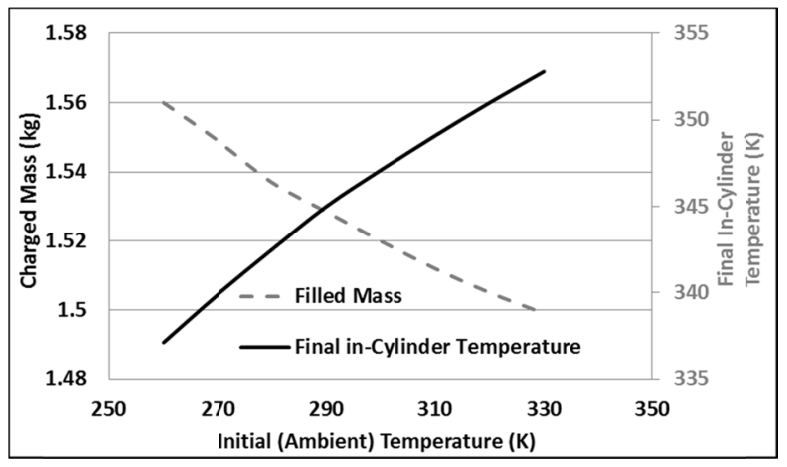

Figure 12: Effect of initial (ambient) temperature on final in-cylinder temperature and charged mass.

\section{CONCLUSION}

The heat characteristics of a hydrogen onboard cylinder during the filling process are very important in view of safety standards. The previous studies, which investigated the filling process thermodynamically, failed to model the heat transfer between the in-cylinder gas and ambient. The CFD studies also cost a lot in time and resources. The current work consists of two parts. In the first part, the fast filling process of a hydrogen cylinder was modelled using the CFD code fluent. Based on the CFD results, a correlation for predicting the inner convective heat transfer coefficient was developed. By knowing the inner convective heat transfer coefficient, the complete and independent thermodynamic modelling of the filling process was carried out in the second part. The complete thermodynamic modelling makes it possible to predict the thermal characteristics of the filling process accurately and quickly.

The results were compared with previous measured values and showed very good agreement. The results also showed that ambient temperature has a big effect on the refueling process, particularly the final in-cylinder temperature and charged mass.

\section{NOMENCLATURE}

$c_{p}, c_{v} \quad$ Constant pressure \&volume specific heats $(\mathrm{kJ} / \mathrm{kg} \mathrm{K})$ 


\section{Greek Letters}

$\alpha \quad$ Heat transfer convection coefficient $\left(\mathrm{W} / \mathrm{m}^{2} \mathrm{~K}\right)$

$\lambda \quad$ Thermal conductivity (W/mK)

$\delta \quad$ Isentropic Exponent

$\rho \quad$ Density $\left(\mathrm{kg} / \mathrm{m}^{3}\right)$

\section{Subscript}

$0 \quad$ Rest condition

i initial or inlet condition

e exit condition

max maximum

$\mathrm{p} \quad$ present time of filling process

$\mathrm{s} \quad$ start of filling process

av average

gen generation

C hydrogen on-board cylinder

$\mathrm{CV}$ control Volume

$\mathrm{R}$ reservoir tank

RA ratio

$\infty \quad$ ambient

\section{REFERENCES}

Chan Kim, S., Hoon Lee, S., Bong Yoon, K., Thermal characteristics during hydrogen fuelling process of type IV cylinder. Int. J. Hydrogen Energ., 35, 6830-35 (2010).
Deymi-Dashtebayaz, M., Farzaneh-Gord, M., Nooralipoor, N., Rastgar, S., The full simulation of rapid refueling of a natural gas vehicle on-board cylinder. Journal of Natural Gas Science and Engineering, 21, 1099-1106 (2014).

Dicken, C. J. B., Merida, W., Measured effects of filling time and initial mass on the temperature distribution within a hydrogen cylinder during refuelling. J. Power Sources, 165, 324-36 (2007).

Dicken, C. J. B., Merida, W., Modelling the transient temperature distribution within a hydrogen cylinder during refuelling. Nume. Heat Tra., Part A, 53, $1-24$ (2008).

Farzaneh-Gord, M., Eftekhari, H., Hashemi, S., Magrebi, M., Dorafshan, M., The effect of initial conditions on filling process of CNG cylinders. The Second International Conference on Modelling, Simulation, and Applied Optimization, Abu Dhabi, UAE, March 24-27 (2007).

Farzaneh-Gord, M., Compressed natural gas single reservoir filling process. Gas Int. Eng. and Manag., 48, 16-18 (2008a).

Farzaneh-Gord, M., Hashemi, S. H., Farzaneh-Kord, A., Thermodynamics analysis of cascade reservoirs filling process of natural gas vehicle cylinders. World Applied Sci. J., 5, 143-149 (2008b).

Farzaneh-Gord, M., Deymi-Dashtebayaz, M., Rahbari, H. R., Studying effects of storage types on performance of CNG filling stations. J. of Nat. Gas Sci. Eng., 3, 334-40 (2011).

Farzaneh-Gord, M., Deymi-Dashtebayaz, M., Rahbari, H. R., Niazmand, H., Effects of storage types and conditions on compressed hydrogen fuelling stations performance. Int. J. Hydrogen Energ., 37, 3500-09 (2012a).

Farzaneh-Gord, M., Deymi-Dashtebayaz, M., Rahbari, H. R., Effects of natural gas compositions on CNG fast filling process for buffer storage system. Oil, Gas Sci. Thec., 1-12 (2012b).

Farzaneh-Gord, M., Deymi-Dashtebayaz, M., Rahbari, H. R., Optimizing compressed natural gas filling stations reservoir pressure based on thermodynamic analysis. Int. J. Exergy, 10, 299-319 (2012c).

Farzaneh Gord, M., Deymi-Dashtebayaz, M., Rahbari, H, R., Effects of gas types and models on optimized gas fuelling station reservoir's pressure. Braz. J. Chem. Eng., 30(2), 399-411 (2013a).

Farzaneh-Gord, M., Deymi-Dashtebayaz, M., Optimizing natural gas fuelling station reservoirs pressure based on ideal gas model. Pol. J. Chem. Technol., 15, 88-96 (2013b).

Heitsch, M., Baraldi, D., Moretto, P., Numerical investigations on the fast filling of hydrogen tanks. Int. J. Hydrogen Energ., 36, 2606-2612 (2011). 
International Standard Organization, Gaseous Hydrogen and Hydrogen Blends Land Vehicle Fuel Tanks Part 1: General Requirements, ISO 15869 (2005).

International Standard Organization, Gas CylindersHigh Pressure Cylinders for the on-Board Storage of Natural Gas as a Fuel for Automotive Vehicles, ISO 11439 (2005).

Liss, W. E., Richards, M., Development of a natural gas to hydrogen fuelling station. Topical Report for US DOE, GTI-02/0193, Sept (2002).

Liss, W. E., Richards, M. E., Kountz, K., Kriha, K., Modelling and testing of fast-fill control algorithms for hydrogen fuelling. 2003 National Hydrogen Association Meeting, March (2003).

Liu, Y. L., Zhao, Y. Z., Zhao, L., Li, X., Chen, H. G., Zhang, L. F., Zhao, H., Sheng, R. H., Xie, T., Hu, D. H., Zheng, J. Y., Experimental studies on temperature rise within a hydrogen cylinder during refuelling. Int. J. Hydrogen Energ., 35, 2627-32 (2010).

Maus, S., Hapke, J., Ranong, N. C., Wuchner, E., Friedlmeier, G., Wenger, D., Filling procedure for vehicles with compressed hydrogen tanks. Int. J. Hydrogen Energ., 33, 4612-21 (2008).

Mohamed, K., Paraschivoiu, M., Real gas simulation of hydrogen release from a high-pressure chamber. Int. J. Hydrogen Energ., 30, 903-912 (2005).

Newhouse, N. L., Liss, W. E., Fast filling of NGV fuel containers. SAE paper -01-3739 (1999).

Nooralipour-Nahavandi, N., Farzaneh-Gord, M., Numerical simulation of filling process of natural gas onboard vehicle cylinder. J. Braz. Soc. Mech. Eng. and Sci., 35, 247-256 (2013).

Oosthuizen, P. H., Carscallen, W. E., Compressible Fluid Flow. McGraw-Hill (1997).
Rigas, F., Sklavounos, S., Evaluation of hazards associated with hydrogen storage facilities. Int. J. Hydrogen Energ., 30,1501-1510 (2005).

Schoenung, S., Ridell, B., Maack, M., Miles, S., His, S., A comparative study of hydrogen refuelling station experience. In: WHEC16-World Hydrogen Energy Conference, Lyon (2006).

Shipley, E., Study of natural gas vehicles during the fast fills process. Thesis for Master of Science, College of Engineering and Mineral Resources at West Virginia University (2002).

Thomas, G., Goulding, J., Munteam, C., Measurement approval and verification of CNG dispensers. NWML KT11 Report (2002).

Tzimas, E., Filiou, C., Hydrogen storage: State-of-theart and future perspective. Petten: European Communities (2003).

Yang, J. C., A thermodynamic analysis of refuelling of a hydrogen tank. Int. J. Hydrogen Energ., 34, 6712-21 (2009).

Zhang, Y. J., Mao, Z. Q., Xie, X. F., Research and application of regenerative fuel cells. Prog. Chem., 18, 635-40 (2006).

Zhao, Y., Liu, G., Liu, Y., Zheng, J., Chen, Y., Zhao, L., Guo, J., He, Y., Numerical study on fast filling of $70 \mathrm{MPa}$ type III cylinder for hydrogen vehicle. Int. J. Hydrogen Energ., 37, 17517-22 (2012).

Zheng, J. Y, Li, L, Chen, R., High pressure steel storage vessels used in hydrogen refuelling station. J. Press Vess-T ASME, 130, 1-3 (2008).

Zheng, J., Ye, J., Yanga, J., Tang, P., Zhao, L., Kern, M., An optimized control method for a high utilization ratio and fast filling speed in hydrogen refuelling stations. Int. J. Hydrogen Energ., 35, 3011-3017 (2010). 